\title{
Decreased basal chloride secretion and altered cystic fibrosis transmembrane conductance regulatory protein, Villin, GLUT5 protein expression in jejunum from leptin-deficient mice
}

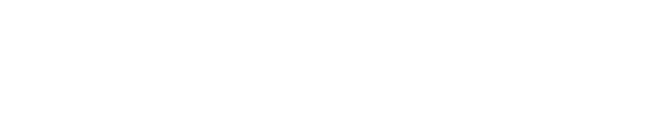

\section{Lana Leung \\ Jonathan Kang \\ Esa Rayyan \\ Ashesh Bhakta \\ Brennan Barrett \\ David Larsen \\ Ryan Jelinek \\ Justin Willey \\ Scott Cochran \\ Tom L Broderick \\ Layla Al-Nakkash}

Department of Physiology,

Arizona College of Osteopathic

Medicine, Midwestern University,

Glendale, AZ, USA
Correspondence: Layla Al-Nakkash Department of Physiology, Midwestern University, 19555 N 59th Avenue, Glendale, AZ, 85308, USA

Tel + I 6235723719

Fax + I 6235723673

Email lalnak@midwestern.edu

\begin{abstract}
Patients with diabetes and obesity are at increased risk of developing disturbances in intestinal function. In this study, we characterized jejunal function in the clinically relevant leptin-deficient ob/ob mouse, a model of diabetes and obesity. We measured transepithelial short circuit current $\left(\mathrm{I}_{\mathrm{sc}}\right)$, across freshly isolated segments of jejunum from 12-week-old ob/ob and lean $\mathrm{C} 57 \mathrm{BL} / 6 \mathrm{~J}$ (female and male) mice. The basal $\mathrm{I}_{\mathrm{sc}}$ was significantly decreased $(\sim 30 \%)$ in the ob/ob mice $\left(66.5 \pm 5.7 \mu \mathrm{A} / \mathrm{cm}^{2}[\mathrm{n}=20]\right)(P<0.05)$ compared with their lean counterparts $\left(95.1 \pm 9.1 \mu \mathrm{A} / \mathrm{cm}^{2}[\mathrm{n}=19]\right)$. Inhibition with clotrimazole $(100 \mu \mathrm{M}$, applied bilaterally) was significantly reduced in the ob/ob mice $(-7.92 \% \pm 3.67 \%[\mathrm{n}=15])(P<0.05)$ compared with the lean mice $(10.44 \% \pm 7.92 \%[\mathrm{n}=15])$, indicating a decreased contribution of $\mathrm{Ca}^{2+}$-activated $\mathrm{K}^{+}\left(\mathrm{K}_{\mathrm{Ca}}\right)$ channels in the ob/ob mice. Inhibition with ouabain $(100 \mu \mathrm{M}$, applied serosally) was significantly reduced in the ob/ob mice $(1.40 \% \pm 3.61 \%, \mathrm{n}=13)(P<0.05)$ versus the lean mice $(18.93 \% \pm 3.76 \%$ $[\mathrm{n}=18]$ ), suggesting a potential defect in the $\mathrm{Na}^{+} / \mathrm{K}^{+}$-adenosine triphosphate (ATP)ase pump with leptin-deficiency. Expression of cystic fibrosis transmembrane conductance regulatory protein (CFTR) (normalized to glyceraldehyde-3-phosphate dehydrogenase [GAPDH]) was significantly decreased $\sim$ twofold $(P<0.05)$ in the ob/ob mice compared with the leans, whilst crypt depth was unchanged. Villi length was significantly increased by $\sim 25 \%(P<0.05)$ in the ob/ob mice compared with the leans and was associated with an increase in Villin and GLUT5 expression. GLUT2 and SGLT-1 expression were both unchanged. Our data suggests that reduced basal jejunal $\mathrm{I}_{\mathrm{sc}}$ in ob/ob mice is likely a consequence of reduced CFTR expression and decreased activity of the basolateral $\mathrm{K}_{\mathrm{Ca}}$ channel and $\mathrm{Na}^{+} / \mathrm{K}^{+}$-ATPase. Understanding intestinal dysfunctions in ob/ob jejunum may allow for the development of novel drug targets to treat obesity and diabetes.
\end{abstract}

Keywords: intestinal secretion, transport, ob/ob, obese, diabetes, small intestine

\section{Introduction}

Diabetes and obesity are both associated with an increased risk and incidence of gastrointestinal disorders. Indeed, slowed gastrointestinal transit time and constipation, ${ }^{1,2}$ and a delayed gastric emptying time or gastroparesis are commonly reported in the obese diabetic patient. ${ }^{3,4}$ The leptin-deficient (ob/ob) mouse is a commonly utilized animal model for type 2 diabetes and obesity. ${ }^{5}$ The phenotype exhibited by this murine model closely mimics the gastrointestinal dysfunction seen clinically, including both slower gastrointestinal transit and gastric emptying time. ${ }^{2}$ In the model of defective leptin-signaling, the $\mathrm{db} / \mathrm{db}$ mouse model of diabetes and obesity, similar phenotypes also have been reported. In addition to the alterations in leptin function inherent to 
the ob/ob mouse, disturbances in intestinal monosaccharide transport appears to also play a role in developing obesity and the diabetic state, via increased fructose absorption, ${ }^{6}$ which is mediated specifically via GLUT transporters. ${ }^{7}$

Within the gastrointestinal tract, typical secretion from intestinal crypts involves $\mathrm{Cl}^{-}$entering the epithelial cells via the $\mathrm{Na}^{+} / \mathrm{K}^{+} / 2 \mathrm{Cl}^{-}$cotransporter, and activation of both apical $\mathrm{Cl}^{-}$channels and basolateral $\mathrm{K}^{+}$channels. Recycling of $\mathrm{K}^{+}$ across the basolateral membrane is required to maintain a driving force for $\mathrm{Cl}^{-}$exit across the apical membrane. The $\mathrm{Na}^{+} / \mathrm{K}^{+}$-adenosine triphosphate (ATP)ase maintains $\mathrm{Na}^{+}$and $\mathrm{K}^{+}$concentration gradients across the membrane. The cystic fibrosis transmembrane conductance regulatory protein (CFTR) $\mathrm{Cl}^{-}$channel is thought to provide the major route for $\mathrm{Cl}^{-}$exit across the apical membrane in the normal murine intestine.$^{8-10}$ However, in the ob/ob mouse jejunum, the role of CFTR in intestinal function remains unknown, and furthermore, no studies have assessed the contribution of key intestinal epithelial transporters that contribute toward chloride secretory function in the ob/ob mouse jejunum.

In this study, we provide an assessment of jejunum basal transepithelial short circuit current $\left(\mathrm{I}_{\mathrm{sc}}\right)$ function, pharmacological profiling via key transporter inhibitors, and the determination of total CFTR protein expression in ob/ob mouse jejunum. In addition, intestinal morphology, along with total intestinal protein expression of SGLT-1, GLUT2, GLUT5, and Villin, in the ob/ob mouse model of obesity and diabetes, was assessed. We hypothesized that the diabetic obese ob/ob mouse model has concomitant dysfunctional jejunum epithelial transport, specifically, deficiencies in jejunal $\mathrm{Cl}^{-}$secretion and that this dysfunction could be attributed to, but not indubitably limited to, an action on CFTR $\mathrm{Cl}^{-}$channel expression and/or function.

\section{Methods}

\section{Mouse model of obesity}

Female and male ob/ob and lean C57BL/6J mice aged 5-6 weeks were purchased from Jackson Laboratory (Bar Harbor, ME, USA) and housed in an animal care facility with 12:12-hour light-dark cycle. The mice consumed food (standard rodent chow) and water ad libitum. Body weight and general health were monitored weekly. At $\sim 12-13$ weeks of age, the mice (ob/ob $[\mathrm{n}=20]$ and lean $[\mathrm{n}=20])$ were asphyxiated in an atmosphere of $100 \% \mathrm{CO}_{2}$, and following this, surgical thoracotomy was performed, to induce pneumothorax. Animal care was conducted in accordance with established guidelines, and all protocols were approved by the Midwestern University Institutional Animal Care and Use Committee. All data shown are the combined data of males and females (equal numbers of each were used per data set).

\section{Assessment of plasma insulin and glucose}

Cardiovascular markers were measured from mouse plasma following the commercial assay kit instructions: glucose was measured with the Wako Autokit Glucose (Wako Pure Chemical Industries, Ltd, Osaka, Japan), and insulin was measured using the Millipore Rat/Mouse Insulin enzymelinked immunosorbent assay (ELISA) (Merck Millipore, Billerica, MA, USA).

\section{Histology and morphology}

Freshly isolated pieces of jejunum were embedded and flash frozen in Optimal Cutting Temperature compound (Tissue-Tek ${ }^{\circledR}$ OCT Compound; Sakura Finetek, Torrance, CA, USA). For hematoxylin and eosin (H\&E) staining, frozen sliced sections $(8-10 \mu \mathrm{m})$ of jejunum were stained with a standard protocol prior to performing the morphometric analyses to evaluate basic histological measurements. In brief, sections were exposed to the following wash protocol: hematoxylin 30 seconds, water rinse 10 seconds, Scott's Bluin Solution 5 seconds, water rinse 10 seconds, 95\% ethanol 5 seconds, eosin 15 seconds, rinses with $95 \%$ ethanol 10 seconds, then $100 \%$ ethanol 10 seconds, followed by xylene 15 seconds. Crypt depth and villi length, along with numbers of goblets cells per crypt and villi, were measured using AxioVision microscope software (Carl Zeiss Meditec, Jena, Germany), from images of H\&E stained jejunum sections. All images were taken at $10 \times$ magnification. Averages of measurements were taken from five separate slices per frozen section of jejunum (ie, per mouse), and data were presented as the average of multiple mice per group.

\section{CFTR, GLUT2, GLUT5, SGLTI, and Villin Western blot analysis}

At collection, jejuna were immediately snap frozen in liquid nitrogen and stored at $-80^{\circ} \mathrm{C}$. Jejuna were later prepared for Western blot analysis by homogenization, and the Western blot protocol used was similar to that described previously. ${ }^{11}$ Briefly, samples were analyzed for protein content, and run on NuPAGE $^{\circledR} 4 \%-12 \%$ Bis-Tris gels (Thermo Fisher Scientific, Waltham, MA, USA) at 150 volts for 1.5 hours. Transfer was carried out for 2 hours at 30 volts, on ice. The blots were incubated with primary antibody to CFTR (CF3) (1:500) (Anti-CFTR [CF3] antibody; Abcam Cambridge, MA, USA), GLUT2 (1:200) (Santa Cruz Biotechnology, Inc., Dallas, TX, USA), GLUT5 (1:200) (Santa Cruz Biotechnology 
Inc.), SGLT-1 (1:200) (Santa Cruz Biotechnology Inc.), and Villin (1:8000) (Abcam) overnight at $4^{\circ} \mathrm{C}$. After washing, the blots were incubated with secondary antibody, anti-rabbit immunoglobulin $(\mathrm{Ig}) \mathrm{G}(\mathrm{H}+\mathrm{L})$ Dylight $^{\mathrm{TM}} 800$ Conjugate $(1: 15,000)$ (Thermo Fisher Scientific, Inc., Waltham, MA, USA), for 1 hour at room temperature. To reprobe for glyceraldehyde 3-phosphate dehydrogenase (GAPDH), blots were incubated with anti-GAPDH primary antibody (1:4000) (Sigma-Aldrich Corp, St Louis, MO, USA) for 1 hour at room temperature. The blots were washed and then reincubated with the appropriate secondary antibody anti-mouse $\operatorname{IgG}(\mathrm{H}+\mathrm{L})(1: 15,000)$ (Dylight; Thermo Fisher Scientific, Inc.). Images of membranes were taken, with all proteins of interest normalized to GAPDH. Band density was analyzed using the Odyssey ${ }^{\circledR} \mathrm{CLx}$ infrared imaging system (LI-COR Biosciences, Inc., Lincoln, NE, USA) and Image Studio ${ }^{\text {TM }}$ Software (LI-COR Biosciences, Inc.).

\section{Bioelectric measurement of intestinal secretion}

Via an abdominal incision, $\sim 5 \mathrm{~cm}$ of mid-jejunum was removed and placed in ice-cold oxygenated Krebs bicarbonate ringer (KBR). Each mouse yielded two to three jejunum pieces, isolated as described previously. ${ }^{11,12}$ Jejunum sections were mounted in an Ussing chamber with a $0.3 \mathrm{~cm}^{2}$ exposed surface area. The $\mathrm{I}_{\mathrm{sc}}\left(\mu \mathrm{A} / \mathrm{cm}^{2}\right)$ was measured via an automatic voltage clamp (VCC-600 Single Channel Clamp; Physiologic Instruments, San Diego, CA, USA), and the experimental conditions and methods were as previously described. ${ }^{11,12}$ Intestinal tissue pieces were maintained in $1 \mu \mathrm{M}$ indomethacin (minimizing tissue exposure to prostanoids generated endogenously due to manipulation and mounting of the tissue) ${ }^{13}$ Glucose $(10 \mathrm{mM})$ was added to the serosal KBR bath, and mannitol $(10 \mathrm{mM})$ was substituted for glucose in the mucosal KBR bath, to avoid an inward current due to $\mathrm{Na}^{+}$-coupled glucose transport. ${ }^{14}$ Once mounted, the serosal side was exposed to tetrodotoxin $(0.1 \mu \mathrm{M})$, minimizing variations in intrinsic intestine neural tone. ${ }^{15}$ Intrinsic neural tone limits the absorptive capacity of the murine mucosa (decreased $\mathrm{I}_{\mathrm{sc}}$ denotes neural block).

\section{Experimental protocols}

Tissues were exposed to KBR (20 minutes) and steady-state basal $\mathrm{I}_{\mathrm{sc}}$ measured during this time. At this time point, the following pharmacological tools were added for 15 minutes: 4,4'-diisothiocyanatostilbene-2,2' -disulfonic acid disodium salt hydrate (DIDS) $(200 \mu \mathrm{M}$, applied bilaterally), or clotrimazole (100 $\mu \mathrm{M}$, bilaterally), or ouabain $(100 \mu \mathrm{M}$, basolaterally) were used to determine the contribution to the anion secretory component by $\mathrm{Ca}^{2+}$-activated $\mathrm{Cl}^{-}$channels, $\mathrm{Ca}^{2+}$-activated $\mathrm{K}^{+}$ $\left(\mathrm{K}_{\mathrm{Ca}}\right)$ channels, and the $\mathrm{Na}^{+} / \mathrm{K}^{+}$-ATPase, respectively. Glucose (10 mM, mucosally) was added at the end of each experiment to stimulate $\mathrm{Na}^{+}$-coupled glucose transport, as an assessment of tissue viability (denoted by $>10 \%$ increase in $\mathrm{I}_{\mathrm{sc}}$ ). Tissues failing to respond to glucose within this parameter were discarded. In addition, $\mathrm{Cl}^{-}$-containing $\mathrm{KBR}$ contained the following: $115 \mathrm{mM} \mathrm{NaCl}, 25 \mathrm{mM} \mathrm{NaHCO}_{3}, 5 \mathrm{mM} \mathrm{KCl}, 1.2$ $\mathrm{mM} \mathrm{MgCl}$, and $1.2 \mathrm{mM} \mathrm{CaCl}_{2}, \mathrm{pH}$ 7.4.

\section{Chemicals}

DIDS was purchased from (Calbiochem ${ }^{\circledR}$; Merck Millipore). Clotrimazole was purchased from MP Biomedicals (Santa Ana, CA, USA). Ouabain was purchased from R\&D Systems (Minneapolis, MN, USA). All other chemicals were obtained from Sigma-Aldrich Corp.

\section{Statistics}

Data are expressed as mean \pm standard error of the mean (SEM). Numbers, in parentheses, represent numbers of tissues used from separate individual mice. Unpaired Student's $t$-tests, were performed using GraphPad (GraphPad Software, Inc., La Jolla, CA, USA), and $P<0.05$ was considered statistically significant.

\section{Results \\ Mouse weights, plasma glucose, and insulin}

The ob/ob mice were twofold heavier compared with their lean counterparts $(51.37 \pm 1.17 \mathrm{~g}[\mathrm{n}=19]$ versus $23.32 \pm 1.00 \mathrm{~g}$ $[\mathrm{n}=14])(P<0.05)$, confirming the obese phenotype of this model. Assessment of plasma glucose demonstrated that ob/ob mice had significantly higher plasma glucose compared with leans: $764.89 \pm 30.75 \mathrm{mg} / \mathrm{dL}(\mathrm{n}=15)$ versus $274.99 \pm 13.25 \mathrm{mg} / \mathrm{dL}(\mathrm{n}=16)(P<0.05)$. Insulin was similarly significantly increased in ob/ob mice compared with lean counterparts: $12.68 \pm 1.58 \mathrm{ng} / \mathrm{mL}(\mathrm{n}=15)$ versus $1.95 \pm 0.16 \mathrm{ng} / \mathrm{mL}(\mathrm{n}=16)(P<0.05)$. We found no difference in the plasma glucose and insulin levels of ob/ob male and female mice.

\section{Using chamber bioelectric measurements}

As shown in Figure 1, after a 20 minute equilibration period, basal $\mathrm{I}_{\mathrm{sc}}$ was significantly decreased in the ob/ob mice compared with lean counterparts $\left(66.53 \pm 5.72 \mu \mathrm{A} / \mathrm{cm}^{2}\right.$ $[\mathrm{n}=20]$, versus $\left.95.11 \pm 9.11 \mu \mathrm{A} / \mathrm{cm}^{2}[\mathrm{n}=19]\right)(P<0.05)$. To assess whether the decrease in basal $\mathrm{I}_{\mathrm{sc}}$ was the result 
of obesity and/or leptin-deficiency, we measured basal I in $\mathrm{db} / \mathrm{db}$ mice, a model of leptin resistance characterized by hyperleptinemia due to a defect in leptin receptor signaling. Interestingly, basal $\mathrm{I}_{\mathrm{sc}}$ was also significantly decreased (39.28 $\left.\pm 2.52 \mu \mathrm{A} / \mathrm{cm}^{2}[\mathrm{n}=6]\right)(P<0.05)$ in $\mathrm{db} / \mathrm{db}$ mice compared with leans. To better assess the role of key epithelial ion channels and transporters that may contribute toward the basal $I_{s c}$, the effects of three pharmacological inhibitors applied for a period of 15 minutes were examined. The application of clotrimazole (100 $\mu \mathrm{M}$ bilaterally), a $\mathrm{K}_{\mathrm{Ca}}$ channel blocker, ${ }^{12,16,17}$ resulted in a significant inhibition in the basal $\mathrm{I}_{\mathrm{sc}}$ postapplication in lean mice but had no inhibitory effect in the ob/ob mice (Figure 2A). There was a significant difference in the $\%$ inhibition of basal $\mathrm{I}_{\mathrm{sc}}$ in ob/ob mice $(-7.92 \% \pm 3.67 \%$ $[\mathrm{n}=15])(P<0.05)$ compared with lean mice $(10.44 \% \pm 7.92 \%$ $[\mathrm{n}=15]$ ) (Figure 2B). The $\mathrm{Ca}^{2+}$-activated $\mathrm{Cl}^{-}$channel inhibitor, DIDS (applied bilaterally, $200 \mu \mathrm{M}$ ), had no inhibitory effect on the basal $\mathrm{I}_{\mathrm{sc}}$ in either ob/ob or lean mice (Figure $2 \mathrm{C}$ and D). Furthermore, application of ouabain, a $\mathrm{Na}^{+} / \mathrm{K}^{+}-$ ATPase pump inhibitor (applied serosally, $100 \mu \mathrm{M}$ ), resulted in a significant inhibition of the basal $\mathrm{I}_{\mathrm{sc}}$ postapplication of ouabain in lean mice, but there was no inhibitory effect in $\mathrm{ob} / \mathrm{ob}$ mice (Figure 2E). There was a significant difference in
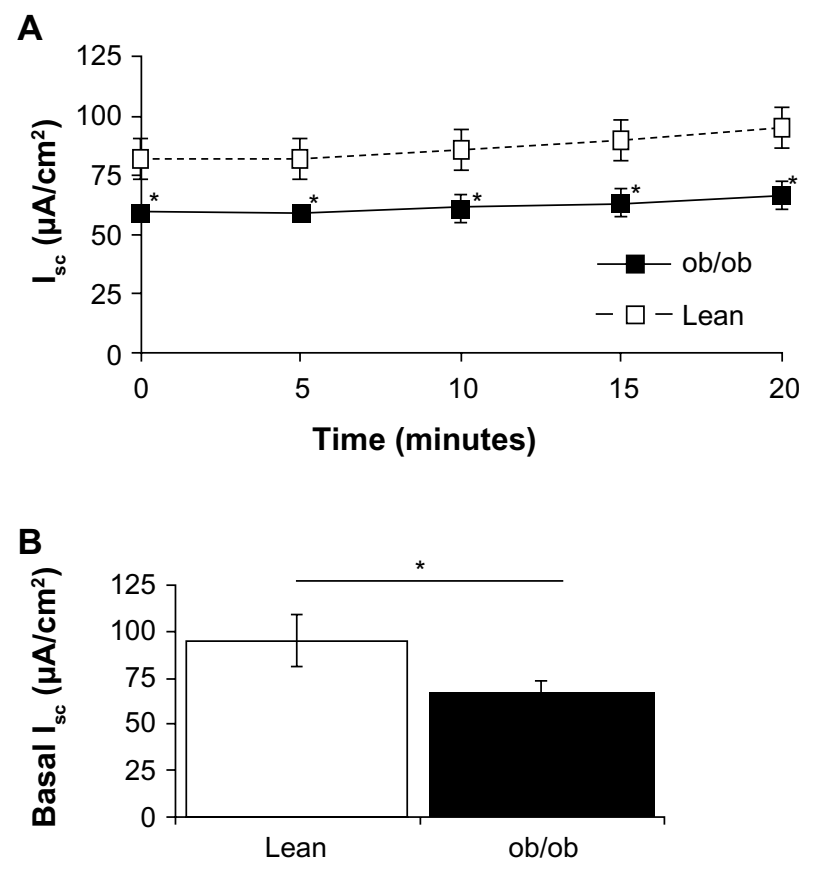

Figure I Jejunum basal $\mathrm{I}_{\mathrm{sc}}$ - (A) Average raw trace data of recordings of basal $I_{s c}\left(\mu \mathrm{A} / \mathrm{cm}^{2}\right)$, from freshly isolated jejunum, recorded from time 0-20 minutes. (B) Average steady state basal $\mathrm{I}_{\mathrm{sc}}$ (at time $=20$ minutes), from lean mice (open bar) and ob/ob mice (solid black bar).

Notes: Values are expressed as mean \pm SEM $(n=19-20)$. *Denotes significant difference from lean $(P<0.05)$.

Abbreviations: $I_{s c}$, transepithelial short circuit current; SEM, standard error of the mean; ob/ob, leptin-deficient. the $\%$ inhibition of the basal $\mathrm{I}_{\mathrm{sc}}$ in ob/ob mice $(1.40 \% \pm 3.61 \%$ $[\mathrm{n}=13])(P<0.05)$ compared with leans $(18.93 \% \pm 3.76 \%$ $[n=18]$ ) (Figure 2F). Taken together, our data suggest that leptin-deficiency alters the expression and function of the key ion transporter function in jejuna.

\section{Jejunum morphology}

To determine whether effects on intestinal basal $\mathrm{I}_{\mathrm{sc}}$ could be associated with changes in murine jejunum morphology, histological sections were stained using H\&E and analyzed for villi length, crypt depth, villi goblet cell number, crypt goblet cell number, and wall thickness (Table 1). Villi length was significantly increased 1.3-fold in ob/ob mice compared with their lean counterparts (Figure 3). However, all other parameters of morphology (crypt depth, number of goblet cells/villi, number of goblet cells/crypt, and wall thickness) were unchanged between the lean and ob/ob groups.

\section{Total CFTR, SGLT-I, GLUT2, GLUT5, and Villin protein expression}

Given that CFTR is the major chloride channel responsible for chloride secretion into the lumen of the jejunum, protein expression of total CFTR protein present was determined utilizing standard Western blot techniques. ${ }^{11,18-20}$ We confirmed a single band with the expected molecular weight of $\sim 170 \mathrm{kD}$ for CFTR. Total CFTR protein expression normalized to GAPDH (Figure 4 ) was significantly decreased ( 40\%) in the ob/ob mice $(0.59 \pm 0.13[\mathrm{n}=16])(P<0.05)$ compared with lean counterparts $(1.00 \pm 0.10[\mathrm{n}=15])$.

To assess potential modifications in the jejunum absorptive processes in the ob/ob mice compared with lean counterparts, total GLUT2, GLUT5, SGLT-1, and Villin protein expression was quantified from jejunum. As shown in Figure 5A, GLUT2 protein expression in the ob/ob mice was comparable $(22.2 \pm 10.7[\mathrm{n}=16])$ with that in their lean counterparts $(15.4 \pm 9.3[\mathrm{n}=16])$. However, the amount of total GLUT5 protein expressed in jejunum was increased 1.5-fold in ob/ob mice $(1.42 \pm 0.15[\mathrm{n}=20])(P<0.05)$ compared with lean mice $(0.94 \pm 0.09[\mathrm{n}=15])$ (Figure 5B). Expression of total SGLT-1 protein was comparable in both ob/ob mice and lean mice $(0.93 \pm 0.15$ and $0.83 \pm 0.16$, respectively) (Figure $5 \mathrm{C})$. Expression of total Villin protein was significantly increased in ob/ob mice compared with leans $(4.37 \pm 2.24$ and $1.09 \pm 0.33$ [each $\mathrm{n}=15])(P<0.05)$ (Figure 5D).

\section{Discussion}

The ob/ob mouse model lacks functional leptin, leading to hyperphagia, obesity, and insulin resistance. ${ }^{21} \mathrm{~A}$ hallmark 

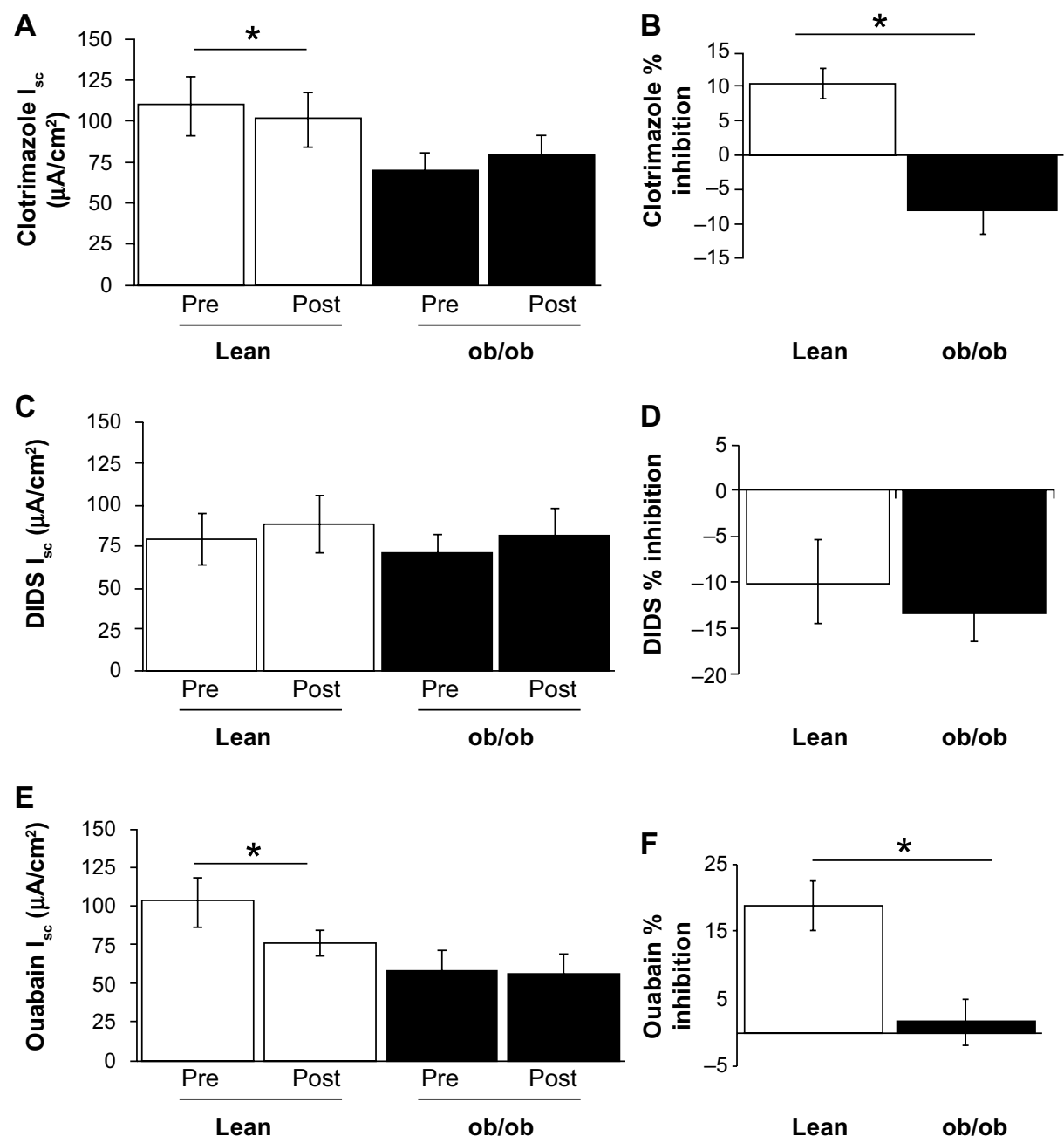

Figure 2 Effect of pharmacological inhibitors on the basal jejunum $\mathrm{I}_{\mathrm{sc}}$. (A) Average initial steady state basal $\mathrm{I}_{\mathrm{sc}}$ (pre) and resulting basal $\mathrm{I}_{\mathrm{sc}} \mathrm{I} 5$ minutes after bilateral application of $100 \mu \mathrm{M}$ clotrimazole (post), in lean (open bars) and ob/ob (solid bars) mice. (B) Percent inhibition of basal $\mathrm{I}_{\mathrm{sc}}$ by clotrimazole (I00 $\mu \mathrm{M}$, bilateral), on lean (open bars) and ob/ob mice (solid black bar). (C) Average initial steady state basal I (pre) and resulting basal I I5 minutes after bilateral application of $200 \mu M$ DIDS (post), in lean (open bars) and ob/ob (solid bars) mice. (D) Percent inhibition of basal I $\mathrm{sc}_{\mathrm{sc}}$ by DIDS (200 $\mu$ M, bilateral), on lean (open bars) and ob/ob mice (solid black bar). (E) Average initial steady state basal $\mathrm{I}_{\mathrm{sc}}$ (pre) and resulting basal $\mathrm{I}_{\mathrm{sc}} 15$ minutes after basolateral application of $100 \mu \mathrm{M}$ ouabain (post), in lean (open bars) and ob/ob (solid bars) mice. (F) Percent inhibition of basal $\mathrm{I}_{\mathrm{sc}}$ by ouabain ( $100 \mu \mathrm{M}$, basolateral), on lean (open bars) and ob/ob mice (solid black bar).

Notes: Values are expressed as mean \pm SEM $(n=13-18)$. *Denotes significant difference from lean $(P<0.05)$.

Abbreviations: DIDS, 4,4'-diisothiocyanatostilbene-2,2'-disulfonic acid disodium salt hydrate; $I_{s c}$, transepithelial short circuit current; SEM, standard error of the mean; ob/ob, leptin-deficient.

feature of this model is hypoleptinemia, rarely a cause of obesity and diabetes in humans but nonetheless, reported clinically. ${ }^{22}$ Among the plethora of pathological conditions in the ob/ob mouse model (other than the typical disturbances in the control of blood glucose homeostasis for which this model is primarily used), intestinal complications that closely mimic those seen clinically in diabetes, such as a slowing of gastrointestinal transit ${ }^{2}$ and delayed gastric emptying (gastroparesis) are common in this model. ${ }^{3}$ The age of the ob/ob mice used in the current study (12-13 weeks) was comparable with that in previous studies demonstrating concomitant changes in intestinal function and hyperglycemia. For instance, gastroparesis has been shown to be associated with hyperglycemia ( twofold increases in plasma glucose) in male ob/ob mice (aged 6-15 weeks) and in male C57Bl/6J mice fed a high fat diet for 14 weeks. ${ }^{23,24}$ Interestingly, in even older mice, aged 33 weeks, significant delays in gastric emptying have been associated with diet-induced obesity. ${ }^{25}$ Gastrointestinal transit has been shown to be significantly delayed in 15-week-old male ob/ob mice and was correlated to increased duodenal secretin content and reduced colonic vasoactive intestinal peptide (VIP) content, but was not correlated to changes in plasma glucose or insulin. ${ }^{2,26}$ Kiely et $\mathrm{al}^{27}$ demonstrated that 13- to 14-week-old male ob/ob mice had slowed gastrointestinal transit time but increased gastric emptying time. Thus, there are noted inconsistencies in the literature, which may be due, in part, to the source of the mice (Europe versus USA). Nonetheless, the ob/ob mice we utilized in this current 
Table I The effects of the obese diabetic state on jejunum morphology

\begin{tabular}{lcc}
\hline & Lean mice & ob/ob mice \\
& $(\mathrm{II}-1 \mathrm{I})$ & $(\mathbf{1 4})$ \\
\hline Villi length $(\mu \mathrm{m})$ & $268.92 \pm 13.88$ & $362.1 \mathrm{I} \pm 19.27^{*}$ \\
Crypt depth $(\mu \mathrm{m})$ & $74.39 \pm 4.34$ & $82.80 \pm 3.36$ \\
Goblet cells/villi & $1.8 \pm 0.3$ & $2.63 \pm 0.5 \mathrm{I}$ \\
Goblet cells/crypt & $1.05 \pm 0.27$ & $1.50 \pm 0.21$ \\
Jejunum wall thickness $(\mu \mathrm{m})$ & $104.89 \pm 9.37$ & $96.07 \pm 9.40$ \\
\hline
\end{tabular}

Notes: Data are expressed as mean \pm SEM. Numbers in parentheses are total numbers of animals/group. *Significantly different to lean mice $(P<0.05)$.

Abbreviations: SEM, standard error of the mean; ob/ob, leptin-deficient.

study, at age 12-13 weeks, were both hyperglycemic and hyperinsulinemic.

The small intestine, specifically the jejunum, is the major site for nutrient absorption and chloride secretion. Despite the clear importance of the jejunum in both absorptive and secretory functions alike, it remains an understudied region in models of diabetes and obesity.

Glucose, galactose, and fructose, the monosaccharide products of digestion, are each absorbed across jejunal epithelium in the enterocytes, via specific transporters. This absorption is dependent upon key transporters, such as the $\mathrm{Na}^{+} /$glucose cotransporter (SGLT-1) and the facilitated diffusion glucose transporters (GLUT2 and GLUT5). On the apical membranes of the intestinal epithelial cells are SGLT-1 transporting glucose and galactose, ${ }^{28,29}$ and GLUT5 transporting fructose. ${ }^{30-32}$ The facilitated transporter GLUT2 is located on the basolateral membrane. ${ }^{33}$ Expression of GLUT2, GLUT5, and SGLT-1 (on the luminal surface of
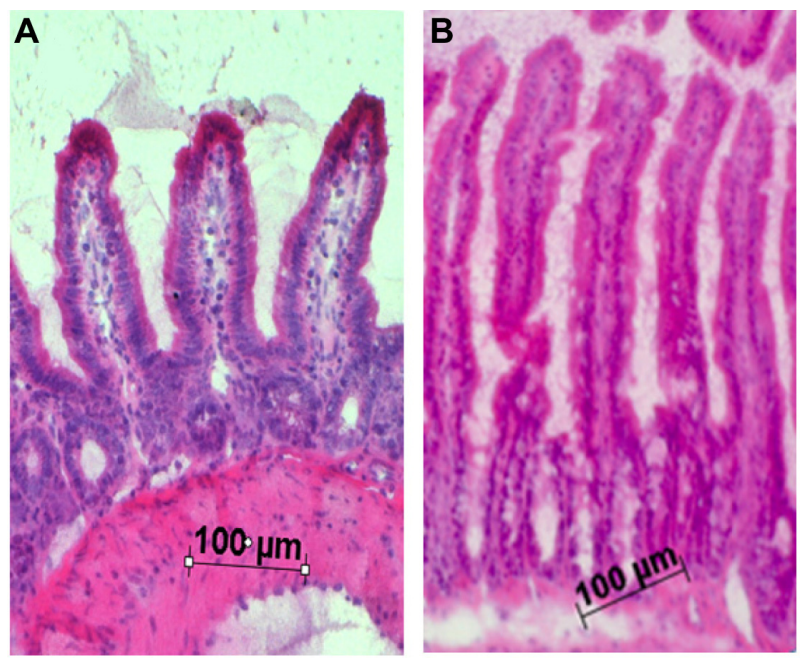

Figure 3 Representative H\&E stained sections from jejunum. (A) Lean control mouse jejunum. (B) ob/ob mouse jejunum.

Note: Images taken at I0× magnification.

Abbreviations: H\&E, hematoxylin and eosin; ob/ob, leptin-deficient.

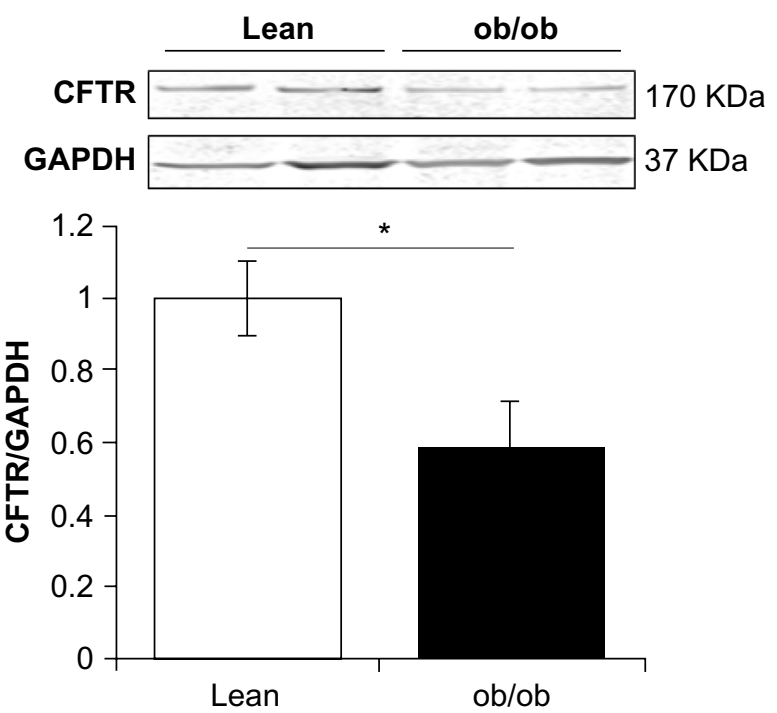

Figure 4 Total CFTR protein expression in murine jejunum. Typical Western blot demonstrating CFTR and GAPDH expression in jejunum from two samples, from both ob/ob and lean mice. CFTR and GAPDH bands were observed at $\sim 170 \mathrm{KDa}$ and $37 \mathrm{KDa}$, respectively.

Notes: Average CFTR/GAPDH ratio comparing ob/ob (solid bar) and lean (open bar) murine jejunum. Values are expressed as mean \pm SEM $(n=15-16)$. *Denotes significant difference from leans $(P<0.05)$.

Abbreviations: CFTR, cystic fibrosis transmembrane conductance regulatory protein; GAPDH, glyceraldehyde-3-phosphate dehydrogenase; SEM, standard error of the mean; ob/ob, leptin-deficient.

epithelial cells) has been demonstrated in male BALB/c murine small intestine. ${ }^{32}$

Our results show significant changes in ob/ob mouse jejunum that were consistent with a predicted increase in absorptive function: 1) increased villi length (ob/ob mouse jejunum villi were $\sim 30 \%$ longer than lean counterparts) and 2) increased GLUT5 expression (ob/ob mouse jejunum expressed 1.5-fold more GLUT5 than did the lean counterparts). These combined data suggest that structural changes and/or alterations in protein expression likely contributed toward an increased absorption and thus, the obesity associated with this model. This has been confirmed by recent evidence indicating that activity of the $\mathrm{H}^{+}$-coupled peptide cotransporter 1 protein, responsible for the absorption of peptide and peptidomimetic drugs, has been shown to be defective in the intestine of ob/ob mice. ${ }^{34}$

Recent evidence by Gorboulev et al, ${ }^{35}$ comparing the role of the SGLT-1 in wild type and SGLT-1(-/-) mice, suggested that, not only is SGLT-1 the major transporter of glucose, it is required to trigger the upregulation of GLUT2. Our data provides evidence that SGLT-1 expression is not upregulated in ob/ob mice, and interestingly, in contrast to previously published studies, ${ }^{35}$ we did not find a corresponding change in GLUT2. These current data suggest that increased villi length in the ob/ob mouse is not always associated with 

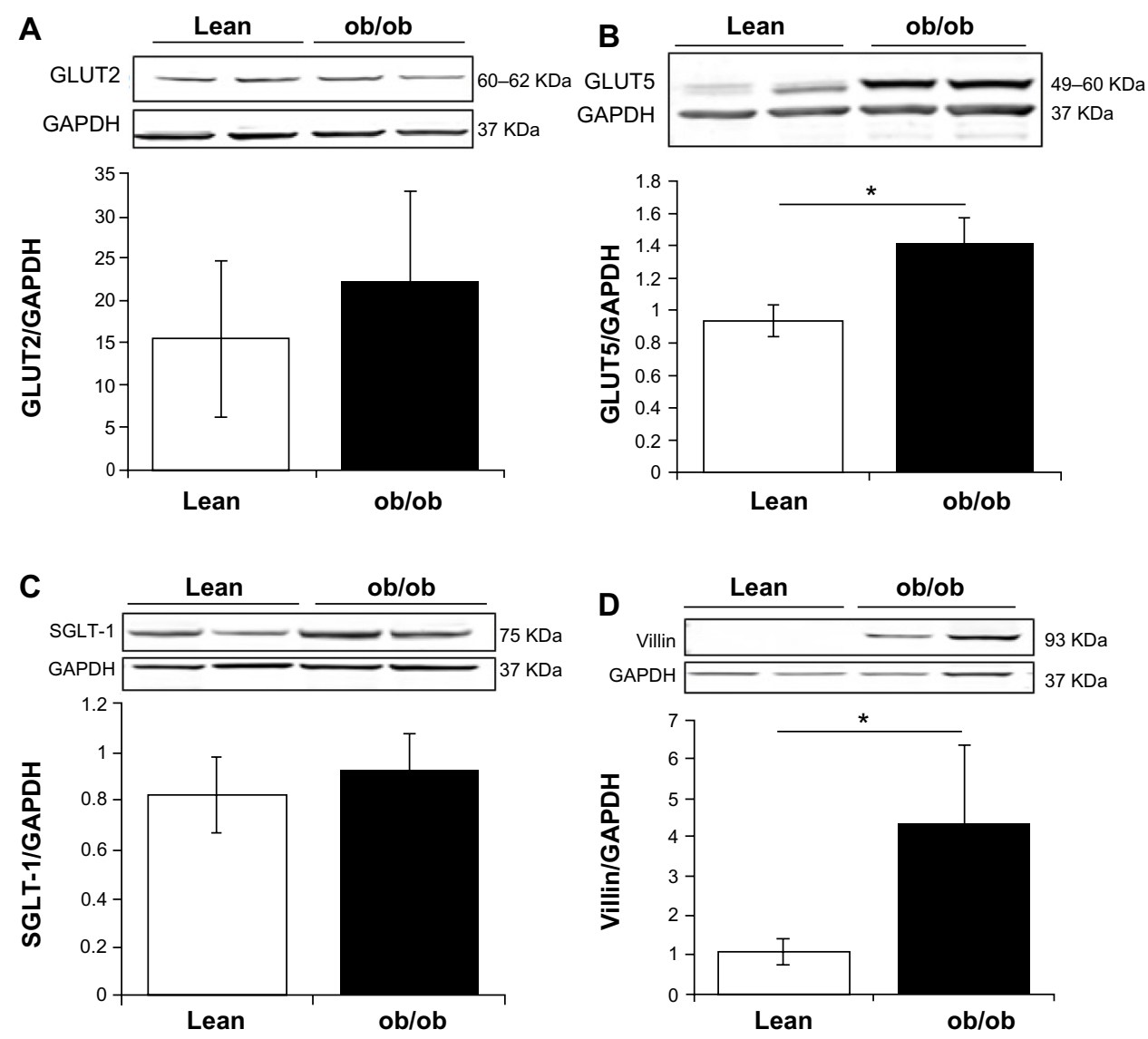

Figure 5 Total GLUT2, GLUT5, SGLT-I, and Villin protein expression in murine jejunum. (A) Typical Western blot demonstrating GLUT2 expression (normalized to GAPDH) in jejunum from two samples from both ob/ob and lean mice. GLUT2 and GAPDH bands were observed at 60-62 KDa and 37 KDa, respectively. Average GLUT2/ GAPDH ratio comparing ob/ob (solid bar) and lean (open bar) murine jejunum. (B) Typical Western blot demonstrating GLUT5 expression (normalized to GAPDH) in jejunum from two samples from both ob/ob and lean mice. GLUT5 and GAPDH bands were observed at 49-60 KDa and 37 KDa, respectively. Average GLUT5/GAPDH ratio comparing ob/ob (solid bar) and lean (open bar) murine jejunum. (C) Typical Western blot demonstrating SGLT-I expression (normalized to GAPDH) in jejunum from two samples from both ob/ob and lean mice. SGLT-I and GAPDH bands were observed at $75 \mathrm{KDa}$ and $37 \mathrm{KDa}$, respectively. Average SGLT-I/GAPDH ratio comparing ob/ob (solid bar) and lean (open bar) murine jejunum. (D) Typical Western blot demonstrating Villin expression (normalized to GAPDH) in jejunum from two samples from both ob/ob and lean mice. Villin and GAPDH bands were observed at $93 \mathrm{KDa}$ and $37 \mathrm{KDa}$, respectively. Average Villin/GAPDH ratio comparing ob/ob (solid bar) and lean (open bar) murine jejunum. Values are expressed as mean \pm SEM $(n=15-20)$. *Denotes significant difference from leans $(P<0.05)$.

Abbreviations: GAPDH, glyceraldehyde-3-phosphate dehydrogenase; SEM, standard error of the mean; ob/ob, leptin-deficient.

parallel increases in key transporters known to be involved in absorptive function. Of note, it has been shown that intestinal absorptive capacity is increased in the ob/ob mouse as a result of increased intestinal length and weight and associated absorptive mucosa. ${ }^{36}$

Optimal fluid secretion is a crucial function of the small intestinal epithelium. We found significant changes in ob/ob mouse gut that were consistent with our predicted decrease in secretory function in this model of obesity: 1) reduced small intestinal basal $\mathrm{I}_{\mathrm{sc}}$ - the ob/ob mouse small intestinal basal $\mathrm{I}_{\mathrm{sc}}$ was decreased by $\sim 30 \mu \mathrm{A} / \mathrm{cm}^{2}$ compared with lean mice; 2) decreased contribution of $\mathrm{Na}^{+} / \mathrm{K}^{+}$-ATPase - the $\mathrm{ob} / \mathrm{ob}$ mouse jejunum was less sensitive to inhibition with ouabain compared with lean counterparts; 3 ) decreased contribution of the $\mathrm{K}_{\mathrm{Ca}}$ channel - the ob/ob mouse jejunum was less sensitive to inhibition with clotrimazole compared with lean counterparts; and 4) decreased CFTR expression - the ob/ob mouse jejunum expressed $40 \%$ less CFTR than did lean counterparts. Taken together, these data suggest that alterations in key epithelial transporter protein expression (and/or function) result in decreased intestinal secretory function and thus may likely contribute toward the obesity associated with this murine model. For example, a decreased secretory function, associated with slowed gastrointestinal transit time, could lend itself to an increased absorptive capacity. Typically, in jejunum tissue, the $\mathrm{CFTR} \mathrm{Cl}^{-}$channel is the major contributor toward epithelial chloride secretion. We found that basal $\mathrm{I}_{\mathrm{sc}}$ was significantly reduced in the ob/ob mouse jejunum, and this was associated with a significant decrease in CFTR expression in the ob/ob mouse jejunum. Our data suggest that the reduced CFTR present in ob/ob murine jejunum contributes toward its dysfunctional $\mathrm{I}_{\mathrm{sc}}$. 
Our data are in contrast to those recently published demonstrating that jejunum $I_{s c}$ was comparable in both $\mathrm{ob} / \mathrm{ob}$ and lean male mice. ${ }^{37}$ The reasons for these disparities in transepithelial $\mathrm{I}_{\mathrm{sc}}$ are unclear but could be related to the source of mouse colony, the age of the mice utilized (12-13 weeks versus 8 weeks), the rodent diets used (Dyets, Inc. [Bethlehem, PA, USA] versus Special Diets Services [Essex, UK]), as well as the severity of the obesity and insulin resistance. Interestingly, in other murine models with dysfunctional intestinal epithelia, non-CFTR chloride channels contribute toward murine intestinal $\mathrm{Cl}^{-}$secretion. For example, in cystic fibrosis mice models, lack of severe intestinal impaction (a consequence of reduced CFTR activity) has been attributed to the presence of alternate chloride channels, specifically $\mathrm{ClC}-2$ and $\mathrm{ClC}-4,{ }^{38,39}$ and $\mathrm{Ca}^{2+}$-activated $\mathrm{Cl}^{-}$channels (mCLCA2 and mCLCA3). ${ }^{40}$ In this study, we found no role for the $\mathrm{Ca}^{2+}$-activated $\mathrm{Cl}^{-}$channel, as indicated by the lack of inhibition by DIDS in both ob/ob and lean mice, confirming our previous work. ${ }^{11}$

It is widely undisputed that secretion from intestinal crypts also involves activation of basolateral $\mathrm{K}^{+}$channels (to both recycle the $\mathrm{K}^{+}$across the basolateral membrane and to maintain a driving force for $\mathrm{Cl}^{-}$exit across the apical membrane), specifically, $\mathrm{K}_{\mathrm{Ca}}$ channels, which have been shown to be inhibited by clotrimazole. ${ }^{11,41,42}$ Our data suggest that application of clotrimazole $(100 \mu \mathrm{M}$, basolaterally) resulted in significantly less inhibition in ob/ob mice compared with lean mice, suggesting that the contribution of basolateral $\mathrm{K}_{\mathrm{Ca}}$ channels toward murine jejunum secretion (and basal $\mathrm{I}_{\mathrm{sc}}$ ) is diminished in the ob/ob mouse. Intestinal jejunal crypt secretion also requires the presence of the $\mathrm{Na}^{+} / \mathrm{K}^{+}$-ATPase to maintain $\mathrm{Na}^{+}$and $\mathrm{K}^{+}$concentration gradients across the membrane. Inhibition of this key transporter (required for optimal epithelial function) with ouabain (100 $\mu \mathrm{M}$, basolaterally) was significantly less in ob/ob mice compared with lean mice, suggesting that the contribution of the $\mathrm{Na}^{+} / \mathrm{K}^{+}$-ATPase toward murine jejunum secretion (basal $\mathrm{I}_{\mathrm{sc}}$ ) is diminished in the ob/ob mouse. Our data suggest that both these essential transporters are likely dysfunctional in the ob/ob mouse jejunum, and perhaps contribute toward its reduced basal $\mathrm{I}_{\mathrm{sc}}$. Future studies will aim to determine whether the inhibition profile we determined using pharmacological tools (clotrimazole and ouabain) is attributed to changes in expression of these important epithelial transporter proteins, and whether the regulation of these transporters is altered in the ob/ob mouse model. Importantly, further assessment is required to ascertain whether disturbances in jejunum epithelial ion transport in the ob/ob mouse are a consequence of inflammatory fluctuations. Indeed, there is evidence that in the inflamed intestine, ionic transport is altered either via changes in expression or function, likely by modification of the signaling pathways of key transporter proteins (ie, the $\mathrm{Na}^{+} / \mathrm{K}^{+}$-ATPase, $\mathrm{Na}^{+} / \mathrm{K}^{+} / 2 \mathrm{Cl}^{-}$-cotransporter, and epithelial sodium channels). ${ }^{43}$ Given that colonic $\mathrm{I}_{\mathrm{sc}}$ has been shown to be reduced (reflective of decreased chloride/ bicarbonate secretion) in inflamed experimental colitis versus noninflamed tissue, ${ }^{43,44}$ it is a possibility that increased inflammatory mediators contributed toward the reduced basal $I_{s c}$ in the ob/ob mouse in this study.

Hypothetically, a reduced crypt depth (ie, less available secretory epithelial cells) in ob/ob jejunum crypts could explain, at least in part, our decreased basal $\mathrm{I}_{\mathrm{sc}}$ (ie, $\mathrm{Cl}^{-}$ secretion); however, we found that crypt depth was similar in ob/ob and lean groups. Whilst the impact of obesity on the epithelial ion transporters involved in the secretory function of jejunum has not previously been reported, it has been shown that obesity disrupts protein expression profiles in the colon. ${ }^{45}$

In conclusion, this study demonstrated a reduced basal $\mathrm{I}_{\mathrm{sc}}$ in ob/ob murine jejunum. We propose that this dysfunction in intestinal epithelial secretion is attributed to a combination of decreases in total epithelial protein expression of CFTR, basolateral $\mathrm{K}_{\mathrm{Ca}}$ channels, and $\mathrm{Na}^{+} / \mathrm{K}^{+}$-ATPase. This trio of incongruities likely contributes to the slowed gastrointestinal transit time typical of the ob/ob mouse and also, human obesity and diabetes syndromes. Future studies will aim to better understand whether cellular regulators of these transporters are also modified in ob/ob mice. We predict that correcting any, or all, of these intestinal epithelial dysfunctions might provide an approach for therapeutic relief of the gastrointestinal complications seen in the obese diabetic phenotype.

\section{Acknowledgments}

The authors would like to thank Dr Timo Rieg (Department of Medicine, University of California, San Diego), for helpful discussion regarding the GLUT2 and GLUT5 Western blots, and Dr Calvin Cotton (Case Western Reserve University), for helpful comments relating to this study. Jonathan Kang, Ashesh Bhakta, and David Larsen were supported by the Midwestern University Doctor of Osteopathic Medicine Summer Fellow Program. This work was supported by Midwestern University Intramural funds (to LA), the Soy Health Research Program (to LA), National Institutes of Health (grant number DK071625-01A2) (to LA), and the Diabetes Action and Research Education Foundation (to TLB). 


\section{Disclosure}

The authors report no conflicts of interest in this work.

\section{References}

1. Bailey CJ, Flatt PR, Deacon CF, Shaw C, Conlon JM. Substance P, neurokinin $\mathrm{A}$, vasoactive intestinal polypeptide and gastrin releasing peptide in the intestine and pancreas of spontaneously obese-diabetic mice. Regul Pept. 1986;16(3-4):339-348.

2. El-Salhy M. Gastrointestinal transit in an animal model of human diabetes type 2: relationship to gut neuroendocrine peptide contents. Ups J Med Sci. 2002;107(2):101-110.

3. Asakawa A, Inui A, Ueno N, et al. Ob/ob mice as a model of delayed gastric emptying. J Diabetes Complications. 2003;17(1):27-28.

4. Asakawa A, Ueno N, Katagi M, et al. Mosapride improves food intake, while not worsening glycemic control and obesity, in ob/ob obese mice with decreased gastric emptying. $J$ Diabetes Complications. 2006;20(1):56-58.

5. Drel VR, Mashtalir N, Ilnytska O, et al. The leptin-deficient (ob/ob) mouse: a new animal model of peripheral neuropathy of type 2 diabetes and obesity. Diabetes. 2006;55(12):3335-3343.

6. Lin S, Yang Z, Liu H, Tang L, Cai Z. Beyond glucose: metabolic shifts in responses to the effects of the oral glucose tolerance test and the high-fructose diet in rats. Mol Biosyst. 2011;7(5):1537-1548.

7. DeBosch BJ, Chi M, Moley KH. Glucose transporter 8 (GLUT8) regulates enterocyte fructose transport and global mammalian fructose utilization. Endocrinology. 2012;153(9):4181-4191.

8. Anderson MP, Welsh MJ. Calcium and cAMP activate different chloride channels in the apical membrane of normal and cystic fibrosis epithelia. Proc Natl Acad Sci U S A. 1991;88(14):6003-6007.

9. Clarke LL, Grubb BR, Yankaskas JR, Cotton CU, McKenzie A, Boucher RC. Relationship of a non-cystic fibrosis transmembrane conductance regulator-mediated chloride conductance to organ-level disease in Cftr(-/-) mice. Proc Natl Acad Sci U S A. 1994;91(2): 479-483.

10. Grubb BR. Ion transport across the normal and $\mathrm{CF}$ neonatal murine intestine. Am J Physiol. 1999;277(1 Pt 1):G167-G174.

11. Al-Nakkash L, Batia L, Bhakta M, et al. Stimulation of murine intestinal secretion by daily genistein injections: gender-dependent differences. Cell Physiol Biochem. 2011;28(2):239-250.

12. Al-Nakkash L. Genistein stimulates jejunal chloride secretion via sex-dependent, estrogen receptor or adenylate cyclase mechanisms. Cell Physiol Biochem. 2012;30(1):137-150.

13. Clarke LL, Harline MC. CFTR is required for cAMP inhibition of intestinal $\mathrm{Na}+$ absorption in a cystic fibrosis mouse model. Am J Physiol. 1996;270(2 Pt 1):G259-G267.

14. Clarke LL, Grubb BR, Gabriel SE, Smithies O, Koller BH, Boucher RC. Defective epithelial chloride transport in a gene-targeted mouse model of cystic fibrosis. Science. 1992;257(5073):1125-1128.

15. Sheldon RJ, Malarchik ME, Fox DA, Burks TF, Porreca F. Pharmacological characterization of neural mechanisms regulating mucosal ion transport in mouse jejunum. J Pharmacol Exp Ther. 1989;249(2):572-582.

16. Hamilton KL, Kiessling M. DCEBIO stimulates Cl- secretion in the mouse jejunum. Am J Physiol Cell Physiol. 2006;290(1):C152-C164.

17. Wu D, Hu Z. Rutaecarpine induces chloride secretion across rat isolated distal colon. J Pharmacol Exp Ther. 2008;325(1):256-266.

18. Bajwa PJ, Lee JW, Straus DS, Lytle C. Activation of PPARgamma by rosiglitazone attenuates intestinal Cl-secretion. Am J Physiol Gastrointest Liver Physiol. 2009;297(1):G82-G89.

19. Chen M, Du J, Jiang W, et al. Functional expression of cystic fibrosis transmembrane conductance regulator in rat oviduct epithelium. Acta Biochim Biophys Sin (Shanghai). 2008;40(10):864-872.

20. Lamhonwah AM, Bear CE, Huan LJ, Kim Chiaw P, Ackerley CA, Tein I. Cystic fibrosis transmembrane conductance regulator in human muscle: Dysfunction causes abnormal metabolic recovery in exercise. Ann Neurol. 2010;67(6):802-808.
21. Zhang Y, Proenca R, Maffei M, Barone M, Leopold L, Friedman JM. Positional cloning of the mouse obese gene and its human homologue. Nature. 1994;372(6505):425-432.

22. Roden M, Ludwig C, Nowotny P, et al. Relative hypoleptinemia in patients with type 1 and type 2 diabetes mellitus. Int JObes Relat Metab Disord. 2000;24(8):976-981.

23. Aviello G, Matias I, Capasso R, et al. Inhibitory effect of the anorexic compound oleoylethanolamide on gastric emptying in control and overweight mice. J Mol Med (Berl). 2008;86(4):413-422.

24. Bhetwal BP, An C, Baker SA, Lyon KL, Perrino BA. Impaired contractile responses and altered expression and phosphorylation of $\mathrm{Ca}(2+)$ sensitization proteins in gastric antrum smooth muscles from ob/ob mice. J Muscle Res Cell Motil. 2013;34(2):137-149.

25. Verhulst PJ, Lintermans A, Janssen S, et al. GPR39, a receptor of the ghrelin receptor family, plays a role in the regulation of glucose homeostasis in a mouse model of early onset diet-induced obesity. J Neuroendocrinol. 2011;23(6):490-500.

26. El-Salhy M, Spångéus A. Gastric emptying in animal models of human diabetes: correlation to blood glucose level and gut neuroendocrine peptide content. Ups J Med Sci. 2002;107(2):89-99.

27. Kiely JM, Noh JH, Graewin SJ, Pitt HA, Swartz-Basile DA. Altered intestinal motility in leptin-deficient obese mice. J Surg Res. 2005; 124(1):98-103.

28. Ferraris RP, Diamond J. Regulation of intestinal sugar transport. Physiol Rev. 1997;77(1):257-302.

29. Ferraris RP. Dietary and developmental regulation of intestinal sugar transport. Biochem J. 2001;360(Pt 2):265-276.

30. Blakemore SJ, Aledo JC, James J, Campbell FC, Lucocq JM, Hundal HS. The GLUT5 hexose transporter is also localized to the basolateral membrane of the human jejunum. Biochem J. 1995;309 (Pt 1):7-12.

31. Shu R, David ES, Ferraris RP. Dietary fructose enhances intestinal fructose transport and GLUT5 expression in weaning rats. Am J Physiol. 1997;272(3 Pt 1):G446-G453.

32. Yoshikawa T, Inoue R, Matsumoto M, Yajima T, Ushida K, Iwanaga T. Comparative expression of hexose transporters (SGLT1, GLUT1, GLUT2 and GLUT5) throughout the mouse gastrointestinal tract. Histochem Cell Biol. 2011;135(2):183-194.

33. Takata K. Glucose transporters in the transepithelial transport of glucose. J Electron Microsc (Tokyo). 1996;45(4):275-284.

34. Hindlet P, Bado A, Farinotti R, Buyse M. Long-term effect of leptin on $\mathrm{H}+$-coupled peptide cotransporter 1 activity and expression in vivo: evidence in leptin-deficient mice. $J$ Pharmacol Exp Ther. 2007;323(1):192-201.

35. Gorboulev V, Schürmann A, Vallon V, et al. Na(+)-D-glucose cotransporter SGLT1 is pivotal for intestinal glucose absorption and glucose-dependent incretin secretion. Diabetes. 2012;61(1):187-196.

36. Ferraris RP, Vinnakota RR. Intestinal nutrient transport in genetically obese mice. Am J Clin Nutr. 1995;62(3):540-546.

37. Stenman LK, Holma R, Gylling H, Korpela R. Genetically obese mice do not show increased gut permeability or faecal bile acid hydrophobicity. Br J Nutr. 2013;110(6):1157-1164.

38. Gyömörey K, Garami E, Galley K, Rommens JM, Bear CE. Non-CFTR chloride channels likely contribute to secretion in the murine small intestine. Pflugers Arch. 2001;443 Suppl 1:S103-S106.

39. Rozmahel R, Wilschanski M, Matin A, et al. Modulation of disease severity in cystic fibrosis transmembrane conductance regulator deficient mice by a secondary genetic factor. Nat Genet. 1996;12(3): 280-287.

40. Leverkoehne I, Holle H, Anton F, Gruber AD. Differential expression of calcium-activated chloride channels (CLCA) gene family members in the small intestine of cystic fibrosis mouse models. Histochem Cell Biol. 2006;126(2):239-250.

41. Devor DC, Singh AK, Gerlach AC, Frizzell RA, Bridges RJ. Inhibition of intestinal Cl- secretion by clotrimazole: direct effect on basolateral membrane K+ channels. Am J Physiol. 1997;273(2 Pt 1): C531-C540. 
42. Hamilton KL, Meads L, Butt AG. 1-EBIO stimulates Cl- secretion by activating a basolateral $\mathrm{K}+$ channel in the mouse jejunum. Pflugers Arch. 1999;439(1-2):158-166.

43. Martinez-Augustin O, Romero-Calvo I, Suárez MD, Zarzuelo A, de Medina FS. Molecular bases of impaired water and ion movements in inflammatory bowel diseases. Inflamm Bowel Dis. 2009;15(1):114-127.
44. Bell CJ, Gall DG, Wallace JL. Disruption of colonic electrolyte transport in experimental colitis. Am J Physiol. 1995;268(4 Pt 1):G622-G630.

45. Padidar S, Farquharson AJ, Williams LM, et al. Impact of obesity and leptin on protein expression profiles in mouse colon. Dig Dis Sci. 2011;56(4):1028-1036.

\section{Publish your work in this journal}

Diabetes, Metabolic Syndrome and Obesity: Targets and Therapy is an international, peer-reviewed open-access journal committed to the rapid publication of the latest laboratory and clinical findings in the fields of diabetes, metabolic syndrome and obesity research. Original research, review, case reports, hypothesis formation, expert opinion and commentaries are all considered for publication. The manuscript management system is completely online and includes a very quick and fair peer-review system, which is all easy to use. Visit http://www.dovepress.com/testimonials.php to read real quotes from published authors.

Submit your manuscript here: http://www.dovepress.com/diabetes-metabolic-syndrome-and-obesity-targets-and-therapy-journal 